\title{
The Onlife Initiative—Conclusion
}

\author{
The Onlife Initiative
}

This is not a conclusion, if a conclusion is meant to be wrapping up what should be remembered from the preceding work. This is not an executive summary either, if an executive summary is all that needs to be read for grasping the added value of an initiative.

The Onlife Manifesto is the agora of this intellectual venture and the accompanying material is a landscape where everyone is invited to walk or navigate at leisure and hopefully be inspired, in a way that leads to revisiting his or her referential frameworks. Indeed, none or few of the recommendations put forward in this work are "ready-to-use": they all require an active reinterpretation or translation by each reader, depending where she or he sits in this hyperconnected era. This being said, we could have skipped the conclusion but chose to end with the following.

The Onlife Manifesto is our contribution on the shifts that policy makers and other stakeholders need to consider in order to shape public and private action in a hyperconnected era. Each word of The Onlife Manifesto has been carefully considered and if only one thing should be read, it is this Manifesto and not this conclusion.

An essential component of this reshaping has to do with design: governance actors ought to pay particular attention to this dimension of the onlife experience: in addition to the traditional hard and soft law-tools of governance, such as national rules, international treaties, or codes of conduct, the governance of a complex multiagent system does increasingly hinge on the technical aspects of design mechanisms.

The reality as it unfolds in a hyperconnected era calls for reengineering concepts and reconsidering conceptual frameworks: this requires a research effort from the social sciences and humanities research community, an open attitude from all scientists towards genuine interdisciplinarity, and a proactive attitude towards citizen's engagement. Horizon 2020 offers a timely and wonderful opportunity to support these three objectives and should be mobilised to this effect.

\footnotetext{
The Onlife Initiative $(\bowtie)$

Oxford, UK

e-mail: claire.lobet@unamur.be 
We consider that the work initiated with the Onlife initiative could usefully be pursued in a second phase. Indeed, several paths have been opened and require further explorations and refinements, notably regarding governance, responsibility and attention.

Open Access This chapter is distributed under the terms of the Creative Commons Attribution Noncommercial License, which permits any noncommercial use, distribution, and reproduction in any medium, provided the original author(s) and source are credited. 